\title{
Sexual Health Promotion and the Attention to the Social Determinants of Health in the Caribbean
}

\author{
Carlos E. Rodriguez-Diaz
}

Published online: 18 August 2013

(C) Springer Science+Business Media New York 2013

\section{Introduction}

Sexual health has been defined in different ways. The approaches vary from technical to practical perspectives highly shaped by historic and sociopolitical experiences. In general, these definitions include that sexual health is the experience of the ongoing process of physical, psychological, and socialcultural well-being related to sexuality. Also that sexual health encompasses not only a positive and respectful approach to sexuality and sexual relationships, as well as the possibility of having pleasurable and safe sexual experiences, free of coercion, discrimination, and violence, but also the inclusion of mental health, responsibility, and the importance of the protection of human rights for health (Edwards and Coleman 2004). On the other hand, sexual health promotion, while a popular term, it is less discussed in the scientific literature and technical documents. Using the frameworks provided by the World Health Organization (WHO 1998) and the Pan American Health Organization and World Association for Sexual Health (2000), we propose understanding sexual health promotion as the process of enabling people to increase control over and thereby improve their sexual health. This approach suggests increasing control over the determinants of sexual health.

The different ways of understanding human conditions such as sexuality are multiplied in multicultural and sociopolitically diverse settings like those present in the Caribbean region. A geographical location encompassed over 30 sovereign states and dependent territories, different colonial histories, multiple governments, and languages, the Caribbean pose variability in the understanding and approaches to promote sexual health and wellbeing. In general, the attention to sexual health in the

C. E. Rodriguez-Diaz $(\bowtie)$

School of Public Health, Medical Sciences Campus, University of Puerto Rico, PO Box 365067, San Juan, Puerto Rico 00936-5067

e-mail: carlos.rodriguez64@upr.edu
Caribbean, as in many other geographical contexts, has been limited and fragmented. The current scientific literature (last 3 years) covering sexual health areas in the Caribbean is mostly associated with reproductive health (Boersma et al. 2012; Claeys 2010; Ferguson et al. 2012; Pottinger et al. 2012; Priestley 2012; van den Brink et al. 2011), sexual violence (Cobbett and Warrington 2013; Lucea et al. 2013; van Wijk and de Brujn 2012), sexuality education (Escobar-Chaves et al. 2011; Hammer et al. 2010), sexual behaviors (Anastario et al. 2010; Ishida et al. 2011; Ortiz et al. 2011), sexually transmitted infections (excluding HIV) (Anderson et al. 2013; Orisatoki and Oguntibeju 2010; Underwood et al. 2010), and other sexual health concerns and problems, particularly cancers (Hennis et al. 2013; Chekuri et al. 2012; Méndez et al. 2013; Underwood et al. 2010). In these recent articles, some island nations or populations are more represented than others and we can speculate that this is associated with the involvement of the academic institutions in these countries as well as the resources allocated for research and dissemination of findings.

Furthermore, the impact that the HIV epidemic has had in the attention of public health issues, including sexual health in the Caribbean, cannot be overseen. Despite the fact that the numbers of new HIV infections, children acquiring HIV infection, and deaths associated with AIDS has declined during the last few years, the Caribbean remains one of the three geographic areas in the globe most heavily affected by the epidemic, where $1 \%$ of adults were living with HIV by 2011 (Joint United Nations Programme on HIV/AIDS 2012). Overall, sexual transmission of HIV has been the leading cause of infection in the region and that may explain the current linkage between HIV and sexual health research in the region.

In fact, some of the works included in this publication were somehow facilitated by the 2011 Caribbean HIV Conference; 
an event that by the theme Strengthening Evidence to Achieve Sustainable Action helped in sharpening the focus on HIV in the Caribbean. This conference provided the opportunity to build networks and collaborations, not only in the area of HIV but also in other fields that require coordinated efforts to promote equity and health across the Caribbean.

\section{Promoting Sexual Health in the Caribbean: From Addressing Disparities to Advocating for Well-Being}

Sexual health promotion requires comprehensive attention to the multiple factors that influence our ability to enjoy our sexuality. In this special publication of the Sexuality Research and Social Policy Journal, authors share their perspectives and findings on multiple dimensions of sexual health of different populations in the Caribbean.

A transversal theme approached by the authors is the inequities in sexual health due to gender inequalities. Gender inequalities are, in general, the product of cultural norms that impact the understanding that individuals may have — or lack of-about sexuality, social roles, and identities. Plummer, based on qualitative interviews with men from seven Anglophone Caribbean countries, evidenced the role of perceptions of masculinity in shaping sexual risk practices among men in the region. His findings illustrate how practices promoted for sexual health protection - such as condom use and partner reduction - can be seen as a failure to fulfill the socially expected gender roles for men. These perceptions of roles and identities must be contextualized in the sociopolitical and cultural scenario of the Caribbean. Doing so, Gillemaut, using an anthropology perspective and qualitative research methods, shared their evidence to understand the role of sociohistorical construction of sexuality and gender in the French territories of Guadeloupe and Guiana. Their findings support the notion that gender inequalities may impact the dynamics associated with HIV-related risk practices among heterosexual individuals in these territories. Similarly, using focus groups, Ocho and Green found that men in Trinidad and Tobago were unwilling to access prostate screening services due to the association of digital rectal examination with anal penetration - a practice participants associated with homosexual behaviors and as an assault to their masculinity.

While health inequities have been widely reported among men who have sex with men (MSM), most of the studies including this group are targeted for HIV and other sexually transmitted infections. There is less information widely available about other sexual health concerns among this population. This is particularly true for MSM in the Caribbean where the study of sexuality in this group can be impacted by the negative perceptions about same-sex practices, homophobia, stigma, and discrimination (Abell et al. 2007; Clatts et al. 2012; Halperin et al. 2009). To contribute to the research among MSM in the region, Colón-López and colleagues shared their findings from a population-based sample in Puerto Rico. These findings support that MSM are engaging in more risky sexual practices than those men who only reported sex with women. Although similar findings have been reported among other populations of MSM, these data should encourage further epidemiological and intervention research to address the impact of social inequities that impact the behavioral risk practices of men beyond the selection of a sexual partner.

Partnering practices should also be addressed in the context of framing gender roles and sexual risks. As reported by McKinney and colleagues, women's male partners were a major factor in the utilization of family planning services among participants of the prevention of mother-to-child transmission programs in La Romana, Dominican Republic. In their study, based on focus groups and semi-structured interviews, attitudes and beliefs about family planning services, mostly grounded in perceptions of gender role, played a major part for the well-being of HIV-positive women.

Often, as a response to the identification of sexual risk practices or the lack of knowledge to protect individuals' health, public health efforts lead to the development of personal health literacy. This is another area for which there is limited research in the Caribbean region. Rivera and colleagues approached the understanding of safer sex informationseeking behaviors in a sample of college students in Puerto Rico with the purpose of contributing with basic information for the development of health communication and other targeted strategies to promote sexual health in this group. The findings of this study support the needs for not only making more reliable sources available, but also to improve the skills among youngsters so they can discern the information they will use to make decisions related to their sexual health.

Within the context of promoting sexual health, the role of the community must be discussed. The community may not only be a source of identity, but may also be the context for risk to or the protection of sexual health. In the Caribbean cultures, religion or organized faith groups play a significant role at multiple levels (Crawford, Rawlins, McGrowder, \& Adams, 2011; Varas-Diaz et al. 2013). Religion, faith-based sections, as well as faith-based organizations (FBO) have been considered in the development of community health efforts in different areas, including reproductive health (Crawford et al. 2011) and HIV prevention and care (Varas-Diaz et al. 2013), among others. Nonetheless, as discussed by Dufour and colleagues on their study based on cross-sectional surveys and interviews, while FBO are engaged in sexual health and HIVrelated initiatives, many are limited by their doctrines and parishioner perceptions and attitudes which lead to stigma and discrimination. Their findings support the notion that "compassion" might be a driver of their role in HIV prevention and sexual health promotion. This should be contrasted 
with a sexual and human rights-based approach to health promotion (Lottes 2013).

As a response to bring social change for health, advocacy has been documented as a major tool for health promotion (Wise 2001), particularly among sexual minorities (PAHO \& WAS 2000). Closing this collection of articles, intersexuality, in particular congenital adrenal hyperplasia, is discussed by Jorge and Agramonte-Machado. Using 10 cases from Cuba and Puerto Rico, their report is an example of how to use data to inform advocacy activities and best practices in the sexual health field. In this case, authors call for action in the medical field to promote the enjoyment of sexuality independently of genital variance.

\section{Sexual Health and Social Determinants of Health}

The findings and perspectives included in this special publication of the Sexuality Research and Social Policy Journal have something in common beyond addressing sexual health; they share a call for the attention of structural levels that are influencing the ability of Caribbean populations to take control of their sexual health; there is a call to address the social determinants of health.

The World Health Organization (2008) has defined the social determinants of health as the complex, integrated, and overlapping social structures and economic systems that include the social environment, physical environment, and health services; structural and societal factors that are responsible for most health inequities. The social determinants of health are shaped by the distribution of money, power, and resources which are themselves influenced by policy choices. The findings in the following articles evidence the needs to address the socioeconomic and political contexts - including policies as well as the cultural and societal norms and values - that impact the sexual health of multiple groups in the Caribbean. For example, gender inequities require addressing the impact of the social gradient, social exclusion, and social support on disenfranchised populations. Among other things, this requires political commitment, explicit policies, sufficient infrastructure, and adequate surveillance. As a response, we should also promote community participation, mobilization, and empowerment over the determinants of health. Furthermore, this requires the involvement of different sectors for health literacy, advocacy, and participatory governance in our region.

We have more to do in order to improve the sexual health status in the Caribbean region. Governments in the region must evidence their commitment with public health by investing in the infrastructures required to reduce disparities. Some national/local and regional policies need to change. Laws that explicitly or implicitly discriminate based on sex, gender identity, or sexual orientation - real or perceivedmust be eliminated. Also, laws and policies that protect from any kind of discrimination at work, in access to housing, and when accessing services must be established. It is required to put in place the corresponding legislative and legal mechanisms to protect most vulnerabilized groups from institutional and interpersonal violence. Similarly, policies and other regulatory mechanisms are required to ensure the provision of comprehensive sexuality education as part of the school curricula and the capacity building on sexual health to healthcare providers.

Dissemination of findings and good practices as well as opportunities to network across nations remains a challenge. This can be addressed through supporting mechanisms, such as conferences and periodic publication, as key features on the Caribbean's health agenda. In the case of HIV as a regional issue, learning from the 2011 Caribbean HIV Conference and as discussed by McLean and colleagues (2012, p. 182), locating a conference "as a key strategic activity on the regional planning agenda begins the process of repositioning health at the center of the region's development agenda." This can be further analyzed to position health equity as the cohesive element for the discussion of other public health issues at conferences and other networking opportunities.

Likewise, sociobehavioral and epidemiological research is required to describe and understand the sexual health characteristics and needs of multiple populations in the Caribbean. Future research is also encouraged to address the macro and meso-level interventions that are required to address the sexual health inequities already documented in our region.

Certainly, HIV continues to capture most of the attention when approaching sexual health promotion in the Caribbean region. While it can be argued that approaching sexual health from the HIV epidemic may obscure other aspects of sexuality, it can also help to explore areas of sexual health and health promotion that have not been approached before. For example, as has been proposed by Mayer et al. (2012) for the HIV epidemic, attention to sexual health also requires the understanding of its multiple dimensions and common vulnerabilities.

Our Caribbean region will continue to evolve and we must respond addressing how these changes may exacerbate disparities across nations related to the understating and protection of sexual diversities. With the appropriate attention to the determinants of health in our region, we can achieve sexually healthy societies.

\section{References}

Abell, N., Rutledge, S. E., McCann, T. J., \& Padmore, J. (2007). Examining HIV/AIDS provider stigma: assessing regional concerns in the islands of the Eastern Caribbean. AIDS Care, 19(2), 242-247.

Anastario, M. P., Tavarez, M. I., \& Chun, H. (2010). Sexual risk behaviors among military personnel stationed at border-crossing zones in 
the Dominican Republic. Revista Panamericana de Salud Publica, 28(5), 361-367.

Anderson, C., Gallo, M. F., Hylton-Kong, T., Steiner, M. J., Hobbs, M. M., Macaluso, M., \& Warner, L. (2013). Randomized controlled trial on the effectiveness of counseling messages for avoiding unprotected sexual intercourse during sexually transmitted infection and reproductive tract infection treatment among female sexually transmitted infection clinic patients. Sexually Transmitted Diseases, 40(2), 105-110.

Boersma, A., Alberts, J., Bruijn, J. D., Mayboom, B. D., \& Kleiverda, G. (2012). Termination of pregnancy in Cracao: need for improvement of sexual and reproductive health care. Global Journal of Health Science, 4(3), 30-38.

Chekuri, A., Bassaw, B., Affan, A. M., Habet, G., \& Mungrue, K. (2012). Knowledge, attitudes, practice on human papilloma virus and cervical cancer among Trinidadian women. Journal of Obstetrics and Genaecology, 32(7), 691-694.

Claeys, V. (2010). Beyond despair - sexual and reproductive health care in Haiti after the earthquake. European Journal of Contraception and Reproductive Health Care, 15(5), 301-304.

Clatts, M. C., Rodríguez-Díaz, C. E., García, H., Vargas-Molina, R. L., Jovet-Toledo, G. G., \& Goldsamt, L. (2012). A preliminary profile of sexual risk in a clinic-based sample of men who have sex with men in Puerto Rico: implications for sexual health promotion interventions. Puerto Rico Health Sciences Journal, 31(3), 154-160.

Cobbett, M., \& Warrington, M. (2013). 'Sometimes it's fun to play with them first': girls and boys talking about sexual harassment in Caribbean schools. Culture, Health, and Sexuality. doi: 10.1080/ 13691058.2013.804585

Crawford, T. V., Rawlins, J., McGrowder, D. A., \& Adams, R. L. Jr. (2011). The church's response to sexual reproductive health issues among youths: Jamaica's experience. Journal of Religion and Health, 50(1), 163-176.

Edwards, \& Coleman. (2004). Defining sexual health: a descriptive overview. Archives of Sexual Behavior, 33(3), 189-195.

Escobar-Chaves, S. L., Shegog, R., Moscoso-Alvarez, M. R., Markham, C., Tortolero-Luna, G., Peskin, M., \& Tortolero, S. (2011). Cultural tailoring and feasibility assessment of a sexual health middle school curriculum: a pilot test in Puerto Rico. Journal of School Health, 81(8), 477-484.

Ferguson, T. S., Tulloch-Reid, M. K., Gordon-Strachan, G., Hamilton, P., \& Wilks, R. J. (2012). National health surveys and health policy: impact of the Jamaica Health and Lifestyle Surveys and the Reproductive Health Surveys. West Indies Medical Journal, 61(4), 372-379.

Halperin, D. T., de Moya, E. A., Pérez-Then, E., Pappas, G., \& Garcia Calleja, J. M. (2009). Understanding the HIV epidemic in the Dominican Republic: a prevention success story in the Caribbean? Journal of Acquired Immune Deficiency Syndromes, 51(Suppl 1), S52-S59.

Hammer, J., Rao, S. P., \& Banegas, M. P. (2010). How much do they know about sexual health?: Knowledge and information seeking behaviors of Spanish-speaking immigrant adolescents in Curacao, Netherlands Antilles. Family and Community Health, 33(4), 285-300.

Hennis, A. J., Wu, S. Y., Nemesure, B., Leske, M. C. (2013). Urologic characteristics and sexual behaviors associated with prostate cancer in an African-Caribbean population in Barbados, West Indies. Prostate Cancer. doi:10.1155/2013/682750.

Ishida, K., Stupp, P., \& McDonald, O. (2011). Prevalence and correlates of sexual risk behaviors among Jamaican adolescents. International perspectives on sexual and reproductive health, 37(1), 6-15.

Joint United Nations Programme on HIV/AIDS. (2012). Global report: UAIDS report on the global AIDS epidemic, 2012. Retrieved July 21, $2013 \mathrm{http}: / / w w w . u n a i d s . o r g / e n / m e d i a /$ unaids/contentassets/ documents/epidemiology/2012/gr2012/20121120_UNAIDS Global_Report_2012_en.pdf
Lottes, I. L. (2013). Sexual rights: meanings, controversies, and sexual health promotion. Journal of Sex Research, 50(3-4), 367-391.

Lucea, M. B., Stockman, J. K., Mana-Ay, M., Bertrand, D., Callwood, G. B., Coverston, C. R., \& Campbell, J. C. (2013). Factors influencing resource use by African American and African-Caribbean women disclosing intimate partner violence. Journal of Interpersonal Violence, 28(8), 1617-1641.

Mayer, K. H., Pape, J. W., Wilson, P., Diallo, D. D., Saavedra, J., Mimiaga, M. J., \& Farmen, P. (2012). Multiple determinants, common vulnerabilities, and creative responses: addressing the AIDS pandemic in diverse populations globally. Journal of Acquired Immune Deficiency Syndrome, 60(Suppl 2), S31-S34.

McLean, R., Nurse, O., Nunes, F., Delph, Y., \& Benjamin, A. (2012). Forging a sustainable response to HIV/AIDS in the Caribbean: the strategic role of a regional conference. Puerto Rico Health Sciences Journal, 31(3), 180-184.

Méndez, K., Romaguera, J., Pérez, C. M., Soto-Salgado, M., TortoleroLuna, G., Palefsky, J. M., \& Ortiz, A. P. (2013). Cervical human papillomavirus infection in a sample of Hispanic women living in Puerto Rico: comparison with cervical cytology reports. Puerto Rico Health Sciences Journal, 32(1), 3-7.

Orisatoki, R. O., \& Oguntibeju, O. O. (2010). Knowledge and attitudes of students at a Caribbean offshore medical school towards sexually transmitted infections and use of condoms. West Indies Medical Journal, 59(2), 171-176.

Ortiz, A. P., Soto-Salgado, M., Suárez, E., Santos-Ortiz, M. C., TortoleroLuna, G., \& Pérez, C. M. (2011). Sexual behaviors among adults in Puerto Rico: a population-based study. Journal of Sexual Medicine, 8(9), 2439-2449.

Pan American Health Organization, and Association for Sexual Health. (2000). Promotion of sexual health: recommendations for action. Available at http://www1.paho.org/English/HCP/HCA/ PromotionSexualHealth.pdf

Pottinger, A. M., Everett-Keane, D., \& McKenzie, C. (2012). Evolution of in vitro fertilization at the University of the West Indies, Jamaica. West Indies Medical Journal, 61(4), 460-462.

Priestley, S. R. (2012). Impaired fertility in Jamaica: evidence from fertility surveys. West Indian Medical Journal, 61(7), 716-725.

Underwood, S. M., Ramsey-Johnson, E., Browne, L., Caines, N., Dean, A., Duval, S., \& Dockery, R. (2010). What women in the United States Virgin Islands still want and need to know about HPV, cervical cancer, and condom use. Journal of the National Back Nurses' Association, 21(1), 25-35.

Van den Brink, M. J., Boersma, A. A., Mayboom-de Jong, B., \& de Bruijn, J. G. (2011). Attitudes towards contraception and abortion among Curacao women. Ineffective contraception due to limited sexual education? BMC Family Practice, 12, 55.

Van Wijk, N. P., \& de Brujn, J. G. (2012). Risk factors for domestic violence in Curacao. Journal of Interpersonal Violence, 27(15), 3032-3053.

Varas-Diaz, N., Neilands, T. B., Contrón-Bou, F., Santos-Figueroa, A. Marzán-Rodríguez, M., \& Marques, D. (2013). Religion and HIV/ AIDS stigma in Puerto Rico: a cultural challenge for training future physicians. Journal of the International Association of Providers in AIDS Care, doi: 10.1177/2325957412472935.

Wise, M. (2001). The role of advocacy in promoting health. Promotion and Education, 8(2), 69-74.

World Health Organization. (1998). Health promotion glossary. WHO/ HPR/HEP/98/1. Geneva.

World Health Organization. (2008). Closing the gap in a generation: health equity through action on the social determinants of health. Report from the Commission on Social Determinants of Health. Retrieved on July 22, 2013 from http://www.who.int/social determinants/thecommission/finalreport/en/index.html 